\title{
The interaction between sensory and tonic factors in the perception of the vertical in pigeons: II. A replication via an alternative procedure'
}

DAVID R. THOMAS, JOSEPH LYONS AND FREDERICK FREEMAN

KENT STATE UNIVERSITY

Ten pigeons were given VI training to peck a key illuminated by a white vertical line in an otherwise dark Skinner box. For 5 Ss the floor was tilted $24^{\circ}$ to the left; for 5 Ss it was tilted $24^{\circ}$ to the right. Generalization testing in extinction to other visual angles with the floor horizontal revealed a displacement of the mode of responding in the direction opposite that to which the floor was tilted in training. The results indicate that apparent vertical is displaced in the same direction and approximately to the same degree as the the floor is tilted. They are thus in complete agreement with other studies in which Ss were trained with the floor flat and tested under various floor tilt conditions.

In a recent study, Thomas \& Lyons (1966) reported evidence for an interaction between sensory and tonic factors in the perception of the visual vertical in pigeons. In two separate experiments, pigeons were trained to peck a key illuminated by a white vertical line in an otherwise dark experimental chamber with the floor in a flat (horizontal) position. After variable interval training, the pigeons were tested in extinction for generalization to other visual angles with the floor inclined $24^{\circ}$ to the left or to the right. The birds showed enhanced responding to angles inclined toward the side to which the floor was tilted. The mode of the generalization gradient (and thus presumably the apparent vertical) was displaced to an angle inclined $30^{\circ}$ from true vertical, and since the floor was inclined $24^{\circ}$ in the same direction, the authors concluded that quite probably no compensation for floor tilt had taken place.

The present study provides an extension of the Thomas \& Lyons (1966) findings. It involves training the Ss to respond to a true vertical $\mathrm{S}^{\mathrm{D}}$ with the floor tilted $24^{\mathrm{O}}$ and then testing for generalization with the floor flat. If the apparent value of the training stimulus is indeed displaced approximately $24^{\circ}$ from true vertical in the direction of the floor inclination, this distortion should be reflected in a displacement of the peak (mode) of the gradient obtained (with the floor flat) in a direction opposite that to which the floor was tilted in training. Method

Subjects. The Ss were 10 experimentally naive adult homing pigeons maintained by restricted feeding at approximately $75 \%$ of their ad libitum weight.

Apparatus. The apparatus consisted of two GrasonStadler pigeon chambers with associated automatic programming and recording equipment. Industrial Electronics Engineers In-line display cells provided the stimuli.
Procedure. Following magazine and key peck training the Ss were given two days of 50 continuous reinforcements each and then 10 daily $1 / 2-\mathrm{hr}$. sessions of $1-\mathrm{min}$. variable interval training. A white vertical line $7 / 8 \mathrm{in}$. high by $1 / 8$ in. wide illuminated the key throughout. training; the chamber was otherwise dark. Throughout training, for Ss No. 1-5 the floor was inclined $24^{\circ}$ to the right; for Ss No. 6-10 the floor was inclined $24^{\circ}$ to the left.

Immediately following the 10th VI training session, the birds were removed from the experimental chambers, the floors were adjusted to a horizontal position, and the birds were returned for generalization testing in extinction. The five test stimuli $\left(30^{\circ}, 60^{\circ}, 90^{\circ}\left(\mathrm{S}^{\mathrm{D}}\right), 120^{\circ}\right.$, and $150^{\circ}$ ) were randomized within a series and six different random series were presented to each $\mathrm{S}$. Stimulus presentations were for $60 \mathrm{sec}$. with no intervening blackouts.

Following this test, all Ss were retrained under the original floor tilt condition for five more days. After the fifth of these, they were given a second generalization test similar to the first.

In order to give each generalization test equal weight, each S's gradient on each test was converted into per cent of total responses to each of the five test stimuli. These per cent scores were then averaged over the two tests and the mean of the average gradients for each

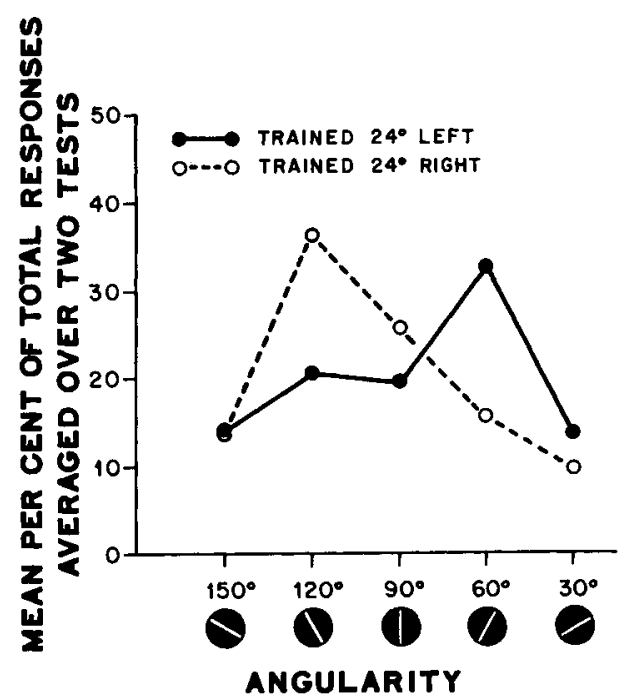

Fig. 1. Mean relative generalization gradients (pooled over two tests) for Ss trained under two different floor tilt conditions. 
group of five Ss is presented in Fig. 1. As predicted, the modes of the obtained generalization gradients are displaced $30^{\circ}$ opposite the direction of the floor tilt employed during training.

For purposes of statistical treatment, again the data were pooled for the two tests. This time the measure employed on each test was the per cent of total generalized responses (i.e., values to stimuli other than $90^{\circ}$ ) to stimulus values less than or greater than $90^{\circ}$. These scores were averaged for the two generalization tests, and then a $t$ test was performed comparing for all $10 \mathrm{Ss}$ the mean per cent of generalized responses to stimuli inclined toward the side to which the floor was also tilted during training vs, the corresponding mean per cent to the opposite side. The value for the opposite side was significantly higher $(t=3.12, d f=9, p<.02)$ and 9 of the 10 Ss showed data in agreement with the group trend.

In another study recently performed by Lyons \& Thomas (1966), the original finding by Thomas \& Lyons (1966) was further extended. Four different groups were trained with the floor flat and tested with the floor inclined $0^{\circ}, 12^{\circ}, 24^{\circ}$, and $36^{\circ}$ to the left. A fifth group was tested with the floor inclined $24^{\circ}$ but with the chamber illuminated; this "lights on" group and the 00 group yielded symmetrical gradients peaking at the $90^{\circ}$ training value; all other groups showed the predicted asymmetry, which was greatest under the $24^{\circ}$ condition.

In combination with the present experiment, the studies by Thomas \& Lyons (1966) and Lyons \& Thomas (1966) demonstrate beyond doubt that, in the absence of veridical visual cues, postural feedback from floor inclination produces a systematic distortion in the perception of visual vertical.

There is no evidence in any of these studies to suggest that an adaptation to the floor tilt occurs such that apparent vertical more closely approaches true vertical with time. Where testing was done under the floor tilt condition there was no evidence for decreasing asymmetry as generalization testing progressed. In the present experiment if adaptation had occurred in the 1/2-hr. training session preceding each test (or cumulated over training sessions) the training stimulus would have effectively been a succession of angles of increasing proximity to $90^{\circ}$. Following such training a relatively flat generalization gradient with much higher response strength at $90^{\circ}$ than that actually obtained would have been expected. Certainly the possibility cannot be precluded that a degree of adaptation occurred which was beyond the measurement sensitivity of these experimental procedures, or that more prolonged exposure to the floor tilt condition might have revealed a measurable adaptation effect. There is, however, no evidence to support such a contention.

The displacement of apparent vertical in the same direction as the floor is inclined has also been demonstrated in humans by La Monica \& Thomas (1966). In the more typical studies in which the human was passively tilted to the side (e.g. Werner, Wapner, \& Chandler, 1951), the distortion tended to be an overcompensation rather than ander-compensation. This difference in procedure and results emphasizes the role of muscular involvement in influencing visual perception and may be interpreted within the framework of Werner \& Wapner's "sensory-tonic field theory of perception" (1952).

\section{References}

La Monica, G., \& Thomas, D. R. Accuracy of perception of the visual vertical as a function of floor inclination. Paper delivered at Midwestern Psychological Association meetings, Chicago, 1966.

Thomas, D. R., \& Lyons, J. The interaction between sensory and tonic factors in the perception of the vertical in pigeons. Percept. \& Psychophys., 1966, 1, 93-95.

Lyons, J., \& Thomas, D. R. The effect of different floor inclinations on the perception of visual vertical in pigeons. Paper delivered at Midwestern Psychological Association meetings, Chicago, 1966.

Werner, H., \& Wapner, S. Toward a general theory of perception. Psychol. Rev., 1952, 59, 324-338.

Wemer, H., Wapner, S., \& Chandler, K. A. Experiments on sensorytonic field theory of perception: II. Effect of supported and unsupported tilt of the body on the visual perception of verticality. J. exp. Psychol., 1951, 42, 346-350.

\section{Note}

1. This research was supported in part by research grant RO 1HD-00903-05 from the National Institute of Health under the direction of the senior author. 